\title{
Assessment of mobility and bioavailability of heavy metals in sewage sludge from Swaziland through speciation analysis
}

\author{
Amos O. Fadiran ${ }^{1}$, Ababu T. Tiruneh ${ }^{2}$, Joseph S. Mtshali ${ }^{2}$ \\ ${ }^{1}$ Department of Chemistry, University of Swaziland, Kwaluseni, Swaziland \\ ${ }^{2}$ Department of Environmental Health Science, University of Swaziland, Mbabane, Swaziland
}

Email address:

fadiran@uniswa.sz (A. O. Fadiran), atiruneh@uniswa.sz (A. T. Tiruneh),jmtshali@uniswa.sz (J. S. Mtshali)

To cite this article:

Amos O. Fadiran, Ababu T. Tiruneh, Joseph S. Mtshali. Assessment of Mobility and Bioavailability of Heavy Metals in Sewage Sludge from Swaziland through Speciation Analysis. American Journal of Environmental Protection. Vol. 3, No. 4, 2014, pp. $198-208$. doi: 10.11648/j.ajep.20140304.14

\begin{abstract}
Speciation analysis of heavy metals in sewage sludge provides a better understanding of the extent of mobility and bioavailability of the different metal fractions and helps in more informed decision making on application of sludge for agricultural purposes. Assessment of bioavailability of metals based on regulations expressed in terms of total metals alone may be conservative and restrictive from the point of view of the use of sludge for agricultural applications. Total metals may also be poor indicators of uptake by plants. Sewage sludge samples generated from seven wastewater treatment plants in Swaziland were analyzed for the four fractions of metals species, namely, exchangeable, reducible, oxidizable and residual fractions. The experimental results indicated that arsenic was predominantly associated with the residual matrix. Chromium was dominantly found in the residual fraction followed by oxidizable fraction. Lead and copper were predominantly associated with oxidizable fraction (bound to organic matter). For more polluted effluents such as Matsapha waste water treatment plant, some metals such as nickel were also found significantly in the mobile fraction. By contrast zinc and to a certain extent nickel were present in significant proportions in the more mobile (exchangeable) fraction. The experimental result indicated that the percentage immobility ranges from $10 \%$ to $70 \%$ with respect to the residual solid fraction of the metals which should be considered as an additional safety factor in the assessment of the suitability of the sludge for agricultural uses with respect to heavy metals.
\end{abstract}

Keywords: Heavy Metals, Bioavailability, Metal Speciation, Metals in Sludge, Exchangeable Metals

\section{Introduction}

It is generally acknowledged that information based on total metals alone is not enough to determine the mobility and bioavailability of heavy metals in sludge and their potential impact on the environment. The bioavailability and toxicity of heavy metals critically depend on the chemical form of heavy metals [2]. Sometimes despite a given metal exceeding the limit in terms of the total metals, it may exist in the less mobile form with limited impact on the environment. The movement of metals in sludge amended soils also depends on the composition of the sludge. For example sewage sludge with high iron oxide can reduce the risk of pollution by heavy metals because of adsorption of heavy metals by the oxides [49]. The associated hazard of heavy metals, therefore, must not be evaluated based on the total metal contents alone [20].

According to Tessier et al. [61], heavy metals forms can be classified into four separate fractions:

1.The exchangeable fraction affected by ionic composition, $\mathrm{pH}$, sorption and desorption processes;

2. The reducible fraction that consists of metals attached to iron and manganese oxides and which are unstable under anoxic conditions:

3. The oxidisable fraction that can be released when the organic matter is degraded leading to release of soluble metals under oxidizing conditions and ;

4. The residual fraction that contains mainly primary and secondary minerals, which may hold metals within their structure.

The above categorization is by no means universal and 
there are various forms of classifications employed for fractionation of metals in sludge. In addition, the chemical extraction procedures used are also variable. There are wide ranges of procedures used for extraction and up to now, there is no one single method that is exclusively suggested and accepted by the scientific community. This has the implication that scientific results obtained by different researchers may, to a certain extent, be difficult to compare. Generally the availability of metals in the different fractions is approximately proportional to the total amount of metal present [45]. This implies that the availability of metals increase with increasing contents of the metals in sewage sludge or with increasing deposition of the metals in the soil with time.

\subsection{Forms of Metal Binding}

\subsubsection{Metals Bound onto Exchangeable Sites}

The exchangeable form of heavy metals can be considered as mobile and it can be used to quantify the short term availability of heavy metals for leaching or uptake by plants [5]. They are considered to be the ones that occur in the ion exchange complexes and which are elucidated depending on the ionic composition of pore waters. They also include metals which are bound to carbonates that can be easily released at lowered soil reaction and are easily available to plants [18]. Silicate minerals provide sites for cation exchange and a few sites for chemical adsorption of heavy metals [8]. Soils and sludges with higher cation exchange capacities have greater tendency for retaining metals. For example, cadmium retention has been observed to be higher in soils with higher cation exchange capacity $[35,28]$. Kuo et al. [28] showed that $\mathrm{Cd}$ retention was greater in fine textured soils with high cation exchange capacity (CEC) compared to coarse-textured soils with lower CEC. McBride et al. [35] showed that $\mathrm{Cd}$ retention was most closely related to the exchangeable base content of the soil. Hydrogen ion activity $(\mathrm{pH})$ is probably the most important factor governing metal speciation, solubility from mineral surfaces, transport, and eventual bioavailability of metals in solutions. $\mathrm{pH}$ affects both solubility of metal hydroxide minerals and adsorption-desorption processes. Most metal hydroxide minerals have very low solubility under high $\mathrm{pH}$ conditions in natural water. Because hydroxide ion activity is inversely related to $\mathrm{pH}$, the solubility of metal hydroxide minerals increases with decreasing $\mathrm{pH}$, and more dissolved metals become potentially available for involvement in biological processes as $\mathrm{pH}$ decreases. Ionic metal species also are commonly the most toxic forms to aquatic organisms [48]. Many metals at high soil contamination levels will form precipitates with oxides, hydroxides and carbonates [21], especially at higher soil $\mathrm{pH}$.

\subsubsection{Metal Adsorbed to Oxides}

Oxides of iron, aluminum and manganese can provide sites for chemical adsorption of metals. These groups of metals include the ones that are bound to manganese oxides and amorphous iron oxides and silicates [41]. Adsorption, which occurs when dissolved metals are attached to surfaces of particulate matter (notably iron, manganese, and aluminum oxide minerals as well as clay, and organic matter), is also strongly dependent on $\mathrm{pH}$ and, of course, the availability of particulate surfaces and total dissolved metal content [3,15]. Cadmium and zinc tend to have adsorption edges at higher $\mathrm{pH}$ than iron and copper, and consequently they are likely to be more mobile and more widely dispersed. Adsorption edges also vary with concentration of the complexing agent; thus, increasing concentrations of complexing agent increases $\mathrm{pH}$ of the adsorption edge [3]. Major cations such as $\mathrm{Mg}^{2+}$ and $\mathrm{Ca}^{2+}$ also compete for adsorption sites with metals and can reduce the amount of metal adsorption [48]. Increase in the $\mathrm{pH}$ of the soil results in precipitation of heavy metals with oxides, hydroxides and carbonates decreasing thereby the mobility of the metals [21]. Metals bound to oxides are thus stable but dangerous because they can be slowly released or changes in the condition in the soil such as reduction-oxidation conditions within the soil can make them available with time. Particulate size and resulting total surface area available for adsorption are both important factors in adsorption processes and can affect metal bioavailability [32]. Metals released into fine-grained soils such as silt-clays can have much lower environmental impact than those released into sands or coarse-grained soils with lower surface area and adsorption.

\subsubsection{Metal Complex in Organics}

Sludge organic matter has the ability to complex and retain metals. Copper is often strongly bound to soil organic matter [36]. Metals bind with functional groups such as carboxyl, phenol, alcohol, carbonyl and metoxyl [55]. There is uncertainty regarding the degree of mobility of metals bound to the organic fraction. According to Brummer [4], the organic and residual forms are stable in the soils and not available to plants. Karapanagiotis [23] also stated that the extractability of metals can be reduced after many years of sludge addition, and this behavior may result from the increase in soil organic matter content, an argument supporting the plateau theory of stabilization of heavy metals in sludge amended soil in the long run. On the other hand, Hanay et al. [19] stated that metals bound to organic matter display a considerable degree of mobility and plant availability. This last statement maybe supported on the basis of the 'time bomb theory' whereby mineralization of the organic matter over a long time can make heavy metals released from the organic fraction later become mobile and available for uptake by plants. The mobility of metals can be enhanced by its complexation with dissolved organic matter (DOC) which increases the extent of leaching of metals in soil $[39,50]$.

Organic compounds such as low molecular weight humus fractions contain phenolic $(\mathrm{Ph}-\mathrm{OH})$ and carboxylic $(-\mathrm{COOH})$ groups in higher concentrations that chelate metals and form stable non soluble complexes. Chelation is 
$\mathrm{pH}$ dependent, because at low $\mathrm{pH}$ the metals must compete with $\mathrm{H}+$ ions for coordination sites on the functional groups [8]. Fluvic acid metal complexes are soluble while humic acid complexes are insoluble [34]. In soluble complexes, metals can be available to plant uptake, while in solid complexes they are immobilized. Bioavailability of metals can diminish because of decrease in organic matter decomposition with time and stabilization of dissolved organic matter and change to insoluble ones [34, 51]. McBride [35] suggested the following sequence of affinity of divalent metal ions for organic matter: $\mathrm{Cu}>\mathrm{Ni}>\mathrm{Pb}>$ $\mathrm{Co}>\mathrm{Ca}>\mathrm{Zn}>\mathrm{Mn}>\mathrm{Mg}$. In general, the more electronegative the metal ion, the stronger the bond formed with organic matter [52].

\subsubsection{Metals Bound into the Soil Residue}

The residual forms of heavy metals are bound to the mineral lattice and can be considered the inactive fraction in terms of chemical processes in the soil. The residual form is divided into heavy metals found in between the mineral layers and the ones specifically adsorbed on the edge of clay layers and unable to be extracted by reagents [6].

The mechanism of accumulation of heavy metals at the interface between the soil/sludge and solution is by adsorption and this chemical process controls the behavior and bio availability of metals [1, 57]. The adsorption sites on the soils include hydroxyl groups of the clay silicate and metal oxides, carboxyl, amine, phenolic and hydroxyl groups existing on the surface of soil organic matter [58]. The mechanism of adsorption may involve a non-specific cation exchange and specific adsorption. The forces involved are physical forces such as the weak van der Waal forces or the electrostatic attraction. Chemical forces involve inner sphere complexation [57]. Several factors influence the adsorption process such as the characteristics of the sites of the solid phase, the metal content and chemistry, concentration of all ligands, soil $\mathrm{pH}$, electrical conductivity and redox potential [25].

\subsection{Speciation of Metals in Soil and Sludge}

The occurrence of heavy metals among the different fractions varies with the metal's chemistry, sludge and soil characteristics. Gawdzik and Gawdzik [18] reported that most of the metals analyzed from a sewage sludge exist in the less mobile fractions (organically bound and residual fractions) while the mobile fractions are found to be low. Stylianou et al. [60] in their speciation analysis of sludge obtained nickel fraction mainly in the exchangeable form followed by organic, residual and reducible forms. Copper was found in decreasing order of organic, exchangeable, residual and reducible forms. Lead was found in the decreasing order of organic, residual, exchangeable, and reducible. Zinc was found in the decreasing order of exchangeable, organic, reducible and residual. Jakobus and Czekała [20] observed the percentage of elements in the easily mobile (exchangeable) forms decreases in the order
$\mathrm{Ni}>\mathrm{Cd}>\mathrm{Zn}>\mathrm{Cr}>\mathrm{Cu}$.

In general, application of sewage sludge leads to an increase in soil heavy metals in the different fractions because of the relatively low concentration of heavy metals in soils [45]. In addition, application of sewage sludge can alter the distribution of heavy metals in soils among the different fractions. This redistribution can happen because of change in $\mathrm{pH}$, organic matter content and other characteristics of the sewage-soil mixture. Kiikkila et al. [26] studied the effect of bio solids as organic immobilizing agents and observed that exchangeable $\mathrm{Cu}$ concentration decreased. Rosazlin et al. [45] found a decrease in the residual fraction of cadmium in soil after application of sewage sludge while the content in the exchangeable fraction increased. The organic fraction of copper in soil increased compared to the sewage sludge organic fraction. This is attributed to formation of soluble organics from the decomposition of sludge that has greater affinity for copper ions. Other researchers also found similar trend of association of copper with organic matter in soil [47, 44]. The exchangeable component of copper tends to decrease after application of sewage sludge to soil due probably to formation of stable complexes between copper and organic matter in the soil and due to sorption by hydrous oxides in the soil as well as formation of insoluble precipitates [53].

According to Rosazlin et al. [45], application of sewage sludge to soil reduced the residual fraction of Nickel and increased the soluble and carbonate fractions. The predominance of nickel in carbonate form also means that liming of sludge would not change the stability of nickel in soil as it already existed in the precipitated (carbonate) form. Soils to which sewage sludge have been applied were seen to show no change of lead metal from the form that occur in the sludge [64]. Lead even though it might be available in the exchangeable form, little is taken up by plants. This is evidence that lead is very immobile in the soil-plant pathway [27]. Increasing application of sewage into soil is seen to increase the fraction of zinc bound to oxides [31]. Lindsay [30] on the other hand reported that the solubility of $\mathrm{Zn}$ in soil solutions increased 100-fold for each unit decrease in $\mathrm{pH}$.

Correlation studies of heavy metal uptake by plants and metal fractions indicated certain association of metal uptake with total metal available, metal available in specific fractions and soil-sludge characteristics. The total concentrations of heavy metals in soil do not indicate the amounts that are available for plant uptake [59]. Total metals may be poor indicators of uptake by plants further justifying the need for fractional analysis of metals in soil and sewage sludge. Rosazlin et al. [45] found significant correlation of cadmium in plant grains with the organically bound fraction of cadmium in the soil. Copper in grains was also positively correlated with the organically bound copper in soil and the copper present in the oxide and carbonate forms. Zhang et al. [67] reported that the zinc available for plant uptake is associated with the Fe-Mn oxide fraction of zinc in the soil. On the contrary, Reneau et 
al. [42] reported negative correlation between zinc plant uptake and zinc present in soil fractions because $\mathrm{Zn}$ in soils is not easily transported into the plant because of migration characteristics in the soil-plant route despite the presence of a high content of heavy metals in soils. Lead in plants was negatively correlated with concentration of lead in soil further confirming the immobility of lead in the soil-plant

path way [45]. Gawdzik and Gawdzik [18] found a decreasing trend between the mobile fraction of heavy metals in sewage sludge and the waste water treatment plant capacities. The recovery rate of speciation analysis of metals is obtained by taking the ratio of the sum of metal species in each fraction to the total metal obtained by a separate acid digestion procedure. The recovery rate has been reported to be in the range between $65.1 \%$ - $106.4 \%$ $[66,19]$.

Table 1. Speciation results for sewage sludge from different researchers [45, 13, 18, 19].

\begin{tabular}{lllll}
\hline & Exchangeable fraction (\%) & Reducible fraction(\%) & Organically bound fraction (\%) & Residual fraction (\%) \\
\hline Cadmium (Cd) & $40, \mathrm{NA}, 10,10.5$ & $14, \mathrm{NA}, 13,19$ & $12, \mathrm{NA}, 34,0.2$, & $34, \mathrm{NA}, 43,70.3$, \\
Nickel $(\mathrm{Ni})$ & $27, \mathrm{NA}, 9,46$ & $11, \mathrm{NA}, 13,12$, & $7, \mathrm{NA}, 38,4$, & $55, \mathrm{NA}, 40,38$, \\
Zinc $(\mathrm{Zn})$ & $18,3.4,16,16$ & $26,92.6,22,22$, & $12,2,12,30$, & $44,2,50,32$, \\
Copper $(\mathrm{Cu})$ & $4,4,2,15$ & $6,60,2,24$ & $56,13,61,42$, & $34,22,35,19$, \\
Lead $(\mathrm{Pb})$ & $12,0.5,1,0.2$ & $2,88,3,43$, & $3,0.5,0, \mathrm{NA}$ & $83,11,92,56.8$ \\
Chromium $(\mathrm{Cr})$ & NA, $0,9,3$, & NA, 50, NA, 5, 10 & NA, 26, 22, 83, & NA, 24, 62, 4, \\
\hline
\end{tabular}

\section{Materials and Methods}

\subsection{Sludge Sampling}

Sludge samples were collected from seven wastewater treatment plants in Swaziland for the analysis of total metals and determination of physico-chemical characteristics of the sludge (Table 2). The wastewater treatment processes that take place in each of the treatment plants are given in Table 2 below. Samples were collected using plastic bags that were pretreated with dilute nitric acid and rinsed with distilled deionized water. Some of the sludge samples collected such as the ones from Matsapha and Ezulwini wastewater treatment works represent different ages as some of the sludge samples from these sites were stored for several years. Both fresh and old dried sludge have been collected separately in order to investigate the variation in metal contents as well as sludge characteristics over time. Sludge samples after collection were dried at room temperature and thereafter stored in a refrigerator at $4{ }^{\circ} \mathrm{c}$.

\subsection{Sample Pretreatment}

The dried sludge samples were first passed through a 2 $\mathrm{mm}$ sieve eliminating roots, stones, plastics, grass and other impurities. The samples were then powdered to fine sizes using mortar and pestle and thoroughly mixed to achieve homogeneity. The powdered sludge sample was then sieved mechanically to obtain a fraction that is less than $63 \mu \mathrm{m}$. The sludge samples after this step were stored in plastic containers at room temperature until they were analyzed.

\subsection{Determination of Sludge Physico-Chemical Characteristics}

A minimum of three replicates from each of the prepared samples as mentioned in sample pretreatment above were taken for the determination of physico-chemical characteristics of the sludge samples. The parameters determined include: $\mathrm{pH}$, electrical conductivity, moisture content, dry solids percentage, volatile and fixed solids, organic matter, organic carbon, available nitrogen, available phosphorous and cation exchange capacity.

\subsection{Total Metal Determination}

The total metal determination was done using two methods for comparison and quality assurance purposes. The methods used were atomic absorption spectrometer (Varian-AAS) and Inductively coupled plasma atomic emission spectrometry (ICP-OES). The metals analyzed include: $\mathrm{Al}, \mathrm{As}, \mathrm{Cd}, \mathrm{Cr}, \mathrm{Co}, \mathrm{Cu}, \mathrm{Fe}, \mathrm{Pb}, \mathrm{Mn}, \mathrm{Mo}, \mathrm{Ni}, \mathrm{Se}, \mathrm{Sn}$, Ti, V, Zn, and Zr. Sample digestion was carried out according to METHOD 3050B of the USEPA: acid digestion of sediments, sludge and soils [63].

For the digestion of sample a $1.000 \mathrm{gm}$. of prepared sludge was weighed using analytical balance of \pm 0.001 precision and transferred to heating mantles with reflux (vapor recovery device). Initially $10 \mathrm{ml}$ of $1: 1 \mathrm{HNO}_{3}$ was added and the sample was heated to $950 \mathrm{C}$ and reflux for 10 to 15 minutes without boiling. After cooling, $5 \mathrm{ml}$ of concentrated $\mathrm{HNO}_{3}$ was then added to the sample and the sample was refluxed for 30 minutes and the procedure of adding $5 \mathrm{~mL}$ of concentrated $\mathrm{HNO}_{3}$ was repeated until no brown fumes were generated indicating completion of reaction with $\mathrm{HNO}_{3}$. The sample was then heated for 2 hours at $95{ }^{\circ} \mathrm{c}$. After completion of the above steps and the sample has cooled, $2 \mathrm{~mL}$ of water and $3 \mathrm{~mL}$ of $30 \% \mathrm{H}_{2} \mathrm{O}_{2}$ were added and the sample was slowly warmed to start the peroxide reaction. The $\mathrm{H}_{2} \mathrm{O}_{2}$ addition was continued in 1 $\mathrm{mL}$ aliquots to a maximum of $10 \mathrm{~mL}$ and the sample was heated for two hours at $95{ }^{\circ} \mathrm{c}$ with a reflux. After completion of the peroxide digestion, the sample was cooled and $10 \mathrm{~mL}$ of concentrated $\mathrm{HCl}$ was added and the sample was slowly heated to $95{ }^{0} \mathrm{C}$ and the heating continued for 15 minutes with a reflux. The digested sample after cooling was filtered through a $0.45 \mu \mathrm{m}$ filter and the filtered digested volume was adjusted to $100 \mathrm{~mL}$ using distilled deionized water. After this the sample was fractionated to two $50 \mathrm{~mL}$ volumes for analysis by the AAS and ICP-AES.

All quality control measures have been observed 
throughout the sample preparation and analysis steps. Distilled-deionized water has been used for dilution and rinsing. All containers and glassware have been thoroughly washed and rinsed with $2 \% \mathrm{HNO} 3$ prior to use in the analysis. Stock solutions of analytical grade chemicals were used for preparation of primary and secondary standards for each of the metals analyzed. For determination of parameters describing sludge characteristics, analytical regent grade chemicals have been used and the standard operating procedures as given for the respective methods were followed. For the determination of method detection limits for metals a number of blank samples prepared using distilled- deionized water were processed through the same steps as those of the samples and metal determinations were similarly made. Spike recovery analysis of each metal was made to determine the recovery due to matrix effects.

Table 2. Wastewater treatment processes that take place at the seven wastewater treatment plants in Swaziland included in the research

\begin{tabular}{llll}
\hline & Location & Wastewater treatment processes & Sludge collected from \\
\hline 1 & Hlathukulu & $\begin{array}{l}\text { Settlement tank, waste stabilization pond, constructed } \\
\text { wetland. }\end{array}$ & From sludge pile taken from waste pond \\
2 & Matsapha & Waste stabilization pond & From stored sludge pile taken from waste pond \\
3 & Nhlambeni & $\begin{array}{l}\text { Settlement, Percolating filter and anaerobic } \\
\text { digester. }\end{array}$ & $\begin{array}{l}\text { Sludge sample taken after anaerobic digestion. Dried sludge } \\
\text { and fresh sludge from sludge drying bed. }\end{array}$ \\
4 & Nhlangano & Waste stabilization pond & Anaerobic pond \\
5 & PiggsPeak & Waste stabilization pond & Anaerobic pond \\
6 & Siteki & Settlement, Percolating filter and anaerobic digester. & Sludge sample after secondary settlement tank \\
7 & Ezulwini & Settlement, Percolating filter and anaerobic & Sludge sample taken after anaerobic digestion. Dried sludge \\
digester. & and fresh sludge from sludge drying bed. &
\end{tabular}

\subsection{Sequential Extraction for Metal Speciation}

The sequential extraction process used in this research is based on the work of the Community Bureau of Reference (formerly called BCR now named Measuring and Testing programme) using the latest recommendation that harmonizes the sequential extraction schemes for the determination of metal fractions $[40,2]$.

\subsubsection{Exchangeable Metal Fraction}

For each of the samples analyzed, $1.000 \mathrm{~g}$ of dry sewage sludge as prepared using the procedure described in sample pretreatment above was extracted with $40 \mathrm{~mL}$ of acetic acid $\left(0.11 \mathrm{~mol} . \mathrm{L}^{-1}\right)$ into $100 \mathrm{~mL}$ centrifuge tubes. For the extraction process, the samples were shaken for sixteen hours at room temperature using a mechanical shaker set at a speed of 40 revolutions per minute. The liquid extract was then separated from the solid residue by centrifugation at a speed of 4000 revolutions per minute. After centrifugation, the liquid portion in the tube was carefully decanted into a dry polyethylene bottle (washed rinsed with distilled and deionized water and rinsed with $2 \%$ nitric acid) and stored at $4{ }^{0} \mathrm{C}$ for analysis of exchangeable metal fraction.

\subsubsection{Reducible Metal Fraction}

The solid residue remaining from the exchangeable metal fraction process described above was extracted with $40 \mathrm{~mL}$ of $0.1 \mathrm{~mol}$. $\mathrm{L}^{-1}$ hydroxyl ammonium chloride $\left(\mathrm{NH}_{2} \mathrm{OH} . \mathrm{HCl}\right)$ at a $\mathrm{pH}$ of 2 maintained by the addition of nitric acid. The extraction and solid-liquid separation processes that followed were similar to the one described for the exchangeable metals extraction above except for the extracting chemical used.

\subsubsection{Oxidizable Metal Fraction}

The residue from the reducible metal fraction process above was treated by careful addition of $30 \%$ hydrogen peroxide $\left(\mathrm{H}_{2} \mathrm{O}_{2}\right)$ in small aliquots. The centrifuge tube was covered with a watch glass at room temperature for 1 hour with occasional manual shaking. Digestion was continued by maintaining a heating temperature of $85{ }^{\circ} \mathrm{C}$ for a period of 1 hour. After this step of heating the cover was removed and the sample was further heated until the volume content in the tube was reduced to $1-2 \mathrm{~mL}$. A second $10 \mathrm{~mL}$ aliquot of hydrogen peroxide was added and the tube was again covered and heated at $85{ }^{\circ} \mathrm{C}$ for one hour. Afterwards, the cover was removed and the volume was reduced as before. A volume of $50 \mathrm{~mL}$ of ammonium acetate $\left(1 \mathrm{~mol} . \mathrm{L}^{-1}\right.$ adjusted to $\mathrm{pH}=2$ with nitric acid) was added to the cool moist residue. The sample was shaken, centrifuged and the extract separated as described in the previous steps above.

\subsubsection{The solid residue fraction}

Sludge residue from the extraction for oxidizable fraction process above was digested following similar procedure used for total metal determination mentioned above.

\section{Results and Discussion}

The results of the ICP-OES based speciation analysis for some of the heavy metals are provided in Table 3 . The fractions determined are for the exchangeable, reducible, oxidizable and solid residue fractions. Arsenic was found predominantly in the oxidizable (organic) fraction (28\%) and the solid residue ( $72 \%$ ) in terms of the median average over the seven wastewater treatment plants. The exchangeable and reducible fractions of arsenic are below the detection limit indicating the limited temporary mobility of arsenic in sludge. Chromium was found in the range: Exchangeable (0\%), Reducible (0\%), Oxidizable (45\%) and solid residue (45\%). Copper was found in the range: Exchangeable (0\%), Reducible (0\%), Oxidizable (83\%) and 
solid residue $(13 \%)$. Lead was found in the range: Exchangeable (0\%), Reducible (0\%), Oxidizable (84\%) and solid residue $(16 \%)$. Zinc was found in the range: Exchangeable (41\%), Reducible (31\%), Oxidizable (24\%) and solids residue $(4 \%)$. Nickel was found in the range: Exchangeable (0\%), Reducible (0\%), Oxidizable (27\%) and solids residue $(72 \%)$.

Table 3. Speciation analysis of sewage sludge samples from seven wastewater treatment plants in Swaziland

\begin{tabular}{|c|c|c|c|c|c|c|c|c|}
\hline \multirow{3}{*}{ Sample } & \multicolumn{8}{|c|}{ Metal species: $E=$ Exchangeable $; R=$ Reducible $; O=$ oxidizable $; S=$ Residue } \\
\hline & \multicolumn{4}{|c|}{ Arsenic } & \multicolumn{4}{|c|}{ Cobalt } \\
\hline & $\mathbf{E}(\%)$ & $\mathbf{R}(\%)$ & $\mathbf{O}(\%)$ & S (\%) & E (\%) & $\mathbf{R}(\%)$ & $\mathbf{O}(\%)$ & $\mathrm{S}(\%)$ \\
\hline Ezulwini & 0 & 0 & 28 & 72 & 0 & 0 & 38 & 62 \\
\hline Hlathukulu & 0 & 0 & 40 & 60 & 0 & 0 & 20 & 80 \\
\hline Matsapha & 0 & 0 & 29 & 71 & 0 & 0 & 30 & 70 \\
\hline Nhlambeni & 0 & 0 & 36 & 64 & 0 & 0 & 36 & 64 \\
\hline Nhlangano & 0 & 0 & 3 & 97 & 0 & 0 & 7 & 93 \\
\hline Pigspeak & 0 & 0 & 21 & 79 & 0 & 0 & 11 & 89 \\
\hline \multirow[t]{3}{*}{ Siteki } & 0 & 0 & 28 & 72 & 0 & 0 & 37 & 63 \\
\hline & Copper & & & & Nickel & & & \\
\hline & E $(\%)$ & $\mathrm{R}(\%)$ & $\mathrm{O}(\%)$ & S (\%) & E $(\%)$ & $\mathrm{R}(\%)$ & $\mathrm{O}(\%)$ & $\mathrm{S}(\%)$ \\
\hline Ezulwini & 2 & 5 & 82 & 10 & 0 & 0 & 25 & 75 \\
\hline Hlathukulu & 0 & 0 & 26 & 74 & 0 & 0 & 28 & 72 \\
\hline Matsapha & 4 & 5 & 83 & 8 & 32 & 11 & 27 & 30 \\
\hline Nhlambeni & 3 & 3 & 83 & 10 & 2 & 0 & 28 & 71 \\
\hline Nhlangano & 0 & 0 & 86 & 14 & 0 & $0 \%$ & 0 & 100 \\
\hline Pigspeak & 0 & 0 & 82 & 18 & 0 & 0 & 8 & 92 \\
\hline \multirow[t]{3}{*}{ Siteki } & 0 & 0 & 87 & 13 & 0 & 0 & 33 & 67 \\
\hline & \multicolumn{4}{|c|}{ Tin } & \multicolumn{4}{|c|}{ Chormium } \\
\hline & E (\%) & $\mathrm{R}(\%)$ & $\mathrm{O}(\%)$ & S (\%) & E (\%) & $\mathrm{R}(\%)$ & O (\%) & $\mathrm{S}(\%)$ \\
\hline Ezulwini & 0 & 0 & 35 & 65 & 0 & 0 & 39 & 61 \\
\hline Hlathukulu & 18 & 0 & 36 & 46 & 0 & 0 & 45 & 55 \\
\hline Matsapha & 0 & 0 & 58 & 42 & 0 & 0 & 56 & 44 \\
\hline Nhlambeni & 0 & 0 & 62 & 38 & 0 & 0 & 64 & 36 \\
\hline Nhlangano & 0 & 0 & 22 & 78 & 0 & 0 & 29 & 71 \\
\hline Pigspeak & 0 & 0 & 26 & 74 & 0 & 0 & 28 & 72 \\
\hline \multirow[t]{3}{*}{ Siteki } & 0 & 0 & 61 & 39 & 0 & 0 & 53 & 47 \\
\hline & \multicolumn{4}{|c|}{ Zinc } & \multicolumn{4}{|c|}{ Lead } \\
\hline & E $(\%)$ & $\mathrm{R}(\%)$ & $\mathrm{O}(\%)$ & S (\%) & E (\%) & $\mathrm{R}(\%)$ & $\mathrm{O}(\%)$ & $\mathrm{S}(\%)$ \\
\hline Ezulwini & 44 & 40 & 13 & 2 & 0 & 0 & 84 & 16 \\
\hline Hlathukulu & 20 & 14 & 42 & 24 & 0 & 0 & 8 & 92 \\
\hline Matsapha & 63 & 20 & 13 & 4 & 0 & 0 & 92 & 8 \\
\hline Nhlambeni & 52 & 32 & 14 & 2 & 0 & 0 & 84 & 16 \\
\hline Nhlangano & 40 & 31 & 28 & 2 & 0 & 0 & 75 & 25 \\
\hline Pigspeak & 41 & 32 & 22 & 4 & 0 & 0 & 89 & 11 \\
\hline Siteki & 34 & 36 & 26 & 3 & 0 & 0 & 84 & 16 \\
\hline
\end{tabular}

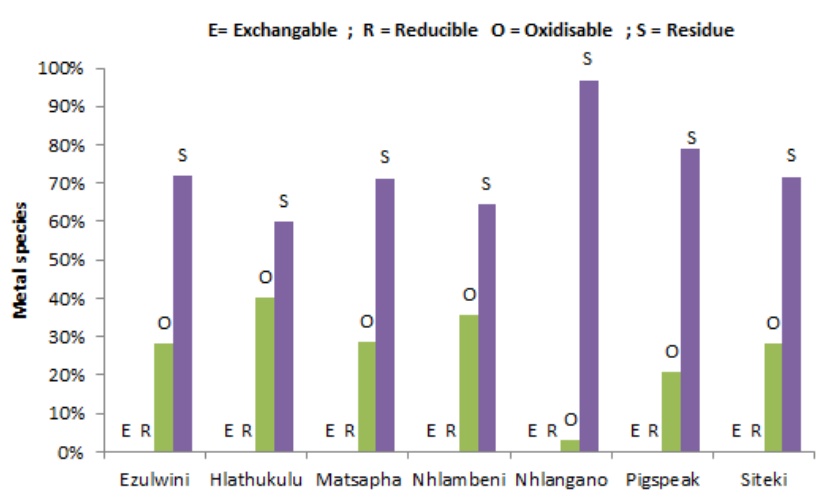

Figure 1. Speciation of arsenic for sewage sludge samples taken from wastewater treatment plants in Swaziland.

The speciation result for arsenic is provided in Figure 1. Arsenic is seen largely associated with the residual matrix for the majority of the sludge analyzed followed by adsorption onto the oxidizable organic matter. The exchangeable and reducible components are negligibly small. The data indicate the high degree of immobility of arsenic in sludge. Similar researches showed arsenic is strongly associated with the residual soil matrix. According to Rivera et al. [43], arsenic is adsorbed into the soil matrix through the formation of an outer sphere complex via electrostatic or van der Waals attractions. As mentioned earlier these forces are strong and irreversible contributing to the high degree of immobility of arsenic. The arsenate fraction As (V) which is present in more oxidized conditions is more strongly adsorbed than the arsenite A (III) fraction. The organic arsenic form which is shown in the data plot can be of concern because of the high mobility of the organic arsenic form in biological systems [54].

The plot of metal fractions of chromium for the sludge samples taken from the seven wastewater treatment plants in Swaziland is provided in Figure 2. The predominant forms of chromium fractions are the oxidizable and solid residue 
fractions while the exchangeable and reducible components are negligibly small. Similar research works also point out that chromium is found in the less mobile oxidizable and residual fractions. Other authors also reported chromium associated with organic matter or precipitated [38]. Hanay et al. [19] also reported the dominant form of chromium in the oxidizable form. This may have a correlation with the oxidizing character of chromium. The trivalent cation is relatively immobile because this form has a strong affinity for negatively-charged ions and colloids [16]. Other authors indicated significant concentration of chromium in the reducible fraction. Czekala [12] for example reported that chromium despite its ability to complex with fulvic acid is often found in the less mobile fractions including metal oxides and hydroxides mainly in the trivalent ion form. Egiarte et al. [13] also reported that chromium was found mainly with the metal oxides (50\%), while $26 \%$ was organically bound and $24 \%$ with the residual fraction.

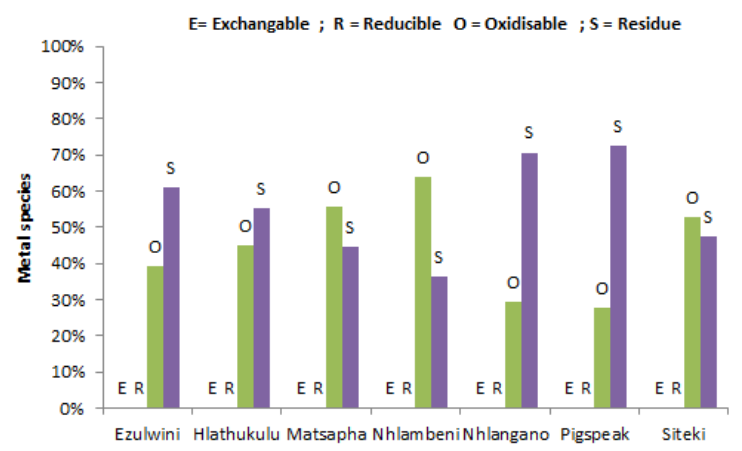

Figure 2. Speciation of chromium for sewage sludge samples taken from wastewater treatment plants in Swaziland.

The plot of copper speciation fractions is given in Figure 3. As can be seen from the figure copper is found predominantly in the oxidizable form followed by the residual fraction which is significantly smaller than the oxidizable fraction. The reducible fraction is limited unlike what has been reported by other researchers. The data in the figure indicate samples from Matsapha, Ezulwini and Nhlambeni treatment plants which receive greater industrial discharges and which as a result contain higher concentrations of copper also have copper available in the mobile fractions. Other authors [9, 33, 7, 46] also showed copper has the lowest mobility. Copper is immobilized by binding with the mineral fraction of the sludge (iron oxides) and in the bonds of organic and residual fractions. The presence of humic acids that are only slightly soluble is of significance in the context of the stability of copper by binding with such compounds [10]. Egiarte et al. [13] found copper fraction in sewage sludge mainly associated with $\mathrm{Fe}$ and $\mathrm{Mn}$ oxides $(60 \%)$ followed by organic fraction $(22 \%)$ and residual fraction (13\%). The exchangeable fraction was only $4 \%$ confirming the lack of mobility of copper in sludge. Several authors found copper mainly associated with the organic fraction [45]. This finding is consistent with the known affinity of copper for organic matter ligands. Hanay et al. [18] also found copper predominantly in the oxidizable fraction. The mobility and bioavailability of copper if any may be controlled by the binding of copper to the soluble part of organic matter because of the special affinity of copper to organic matter [22].

Figure 4 shows a plot of the speciation data of Nickel for the sludge samples analyzed. While Nickel is found predominantly in the oxidizable and residual forms for several samples, the data from the Matsapha sludge sample shows significant fraction present also in the exchangeable and reducible forms. The cadmium data is not presented because the cadmium concentrations were below the detection limits for all the samples analyzed. Nickel and Cadmium are often found in greater quantities in the mobile fractions [22]. Within organic matter they have a preferential bonding with the largely soluble fulvic acids which partly explains their high degree of mobility $[5,10]$. ). Hanay et al. [19] also indicated the predominant form of nickel in the exchangeable form. Chelopeka [11] indicated that cadmium that is often associated with carbonate in sewage sludge can become easily exchangeable and mobile in soil under acidic conditions. The part of cadmium that is in exchangeable form is loosely bound with the surface of clay rather than forming a stronger oxide adsorption and can be easily released into solution [62]. Cadmium is, therefore, easily available for plant uptake.

On the other hand, Rosazlin et al. [45] found higher form of cadmium in the residual fraction (34\%) followed by the exchangeable form (24\%). Hanay et al. [19] also found higher fraction of Cadmium in the residual. This finding is also supported by Wang et al. [65]. Rosazlin et al. [45] reported a higher concentration of zinc in the residual form $(55 \%)$ followed by the carbonate form $(22 \%)$. Cadmium is known to bind rather loosely with organic matter and could be extracted easily in the exchangeable portion. Cadmium, as such does not appear to form strong organic complexes $(58,24]$. Salas et al. [47] also reported low concentration of cadmium bound with organic matter.

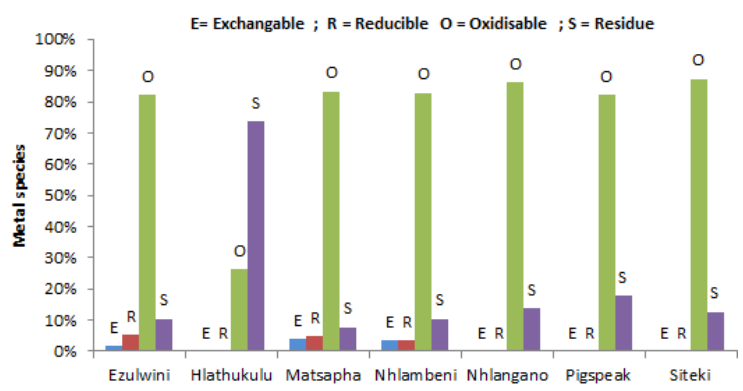

Figure 3. Speciation of copper for sewage sludge samples taken from wastewater treatment plants in Swaziland.

The speciation data for lead is plotted in Figure 5. Lead is seen predominantly associated with the oxidizable fractions while the mobile exchangeable and reducible fractions are negligibly small for all the samples analyzed. Lead is reported to have low mobility although significant concentration can be found in the metal oxide fractions. According to Egiarte et al. [13], lead is associated mainly 
with Fe-Mn oxides (89\%) followed by residual fraction (11\%) and the remaining (1\%) distributed among other fractions.

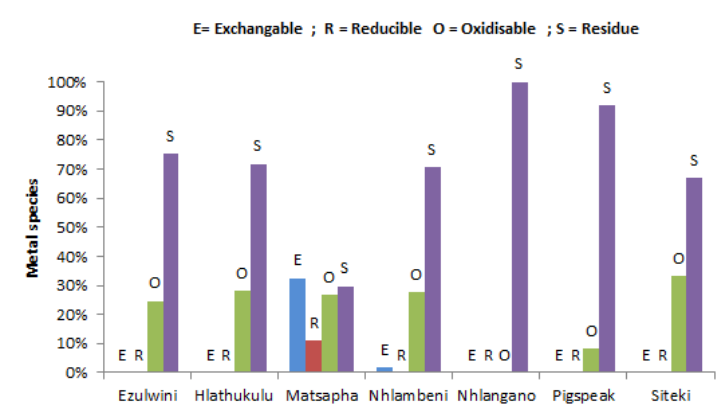

Figure 4. Speciation of nickel for sewage sludge samples taken from wastewater treatment plants in Swaziland.

The mobility of lead as such is limited. Other authors have also reported a very low labile form of lead [29]. Forbes et al. [17] and Eick et al. [14] also reported low solubility of $\mathrm{Pb}$ and its high affinity for metal oxides. Rosazlin et al. [45] also reported a higher percentage of lead in the residual fraction (84\%) followed by exchangeable form $(9 \%)$. Other reports suggest low availability of lead in the exchangeable form. Other researchers also found $\mathrm{Pb}$ to be principally distributed between oxidizable and residual fractions $[65,66]$. According to Silvera and Sommer [53], a higher exchangeable form of lead was found in air dried sewage sludge than in wet sludge (indicating the effect of drying on sludge samples).

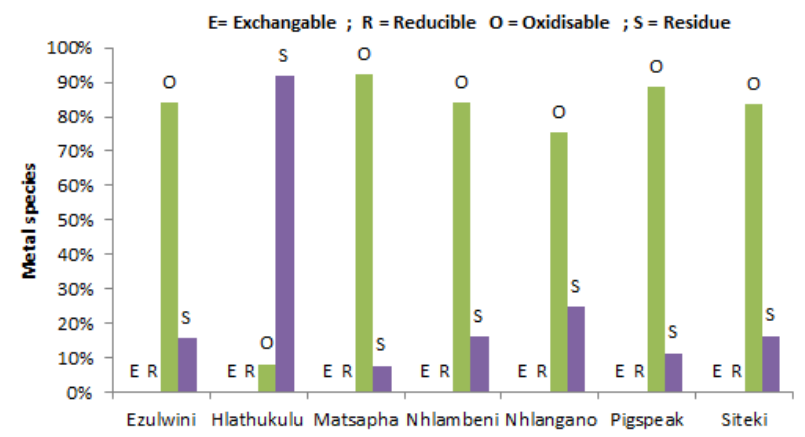

Figure 5. Speciation of lead for sewage sludge samples taken from wastewater treatment plants in Swaziland.

The speciation data for zinc is plotted in Figure 6. As can be seen from the figure zinc is found in the exchangeable and reducible fractions as well as the oxidizable and residual portions of the sludge. The significant concentrations of zinc in the exchangeable and reducible fractions indicate the higher mobility of zinc. McLean and Bledsoe [37] stated that zinc can exist in considerable fraction in the exchangeable form, mainly as carbonate, and its stability is $\mathrm{pH}$ dependent. Zinc is also seen to absorb largely on oxides, organics and residual fractions and the stability of zinc increases with increasing $\mathrm{pH}$ [4]. Egiarte et al. [13] reported zinc mainly associated in iron, manganese and aluminum oxides (93\%) while the remaining $7 \%$ was distributed among the other fractions. Co-precipitation and occlusion of $\mathrm{Zn}$ with Fe and $\mathrm{Al}$ oxyhydroxides may become an important mechanism for retention of $\mathrm{Zn}$ in these wastes other authors [33, 45] reported zinc concentration mainly in the residual form (43\%) followed by Fe-Mn oxides (27\%). Hanay et al. [19] also reported zinc primarily associated with the residual and oxidizable fractions. Sommers [56] suggested co-precipitation during sewage treatment as possible mechanism for the association of zinc with iron and manganese oxides.

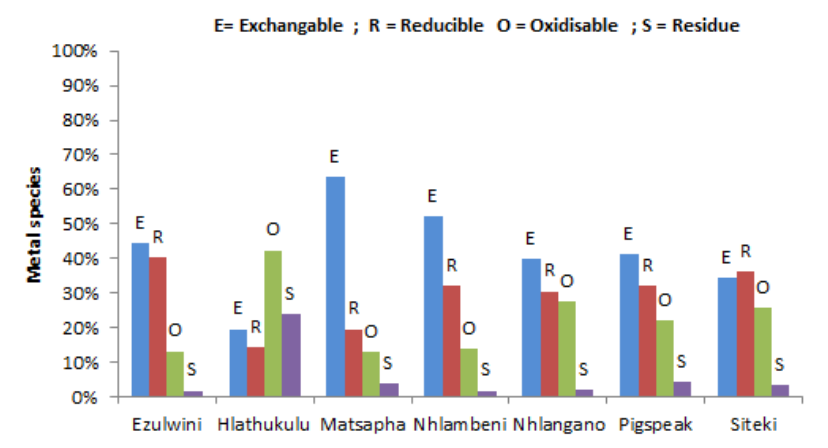

Figure 6. Speciation of zinc for sewage sludge samples taken from wastewater treatment plants in Swaziland.

\section{Conclusion}

The analysis data showed that for most of the metals including, arsenic, chromium, lead, copper, significant fractions of the metals are associated with the oxidizable organic and residual fractions. The affinity of copper and lead for the organic matter and the residual matrix is supported by the results of the analysis that show higher fractions of the copper and lead bound in these fractions. The order of adsorption of metal species onto the organic matter is revealed by the data obtained for the oxidizable fraction which follows the trend (according to median averages): $\mathrm{Pb}(84 \%)>\mathrm{Cu}(83 \%)>\mathrm{V}(57 \%)>\mathrm{Cr}(45 \%)>\mathrm{Fe}$ $(37 \%)>\mathrm{Sn}(36 \%)>\mathrm{Co}(30 \%)>\mathrm{As}(28 \%)>\mathrm{Ni}(27 \%)>\mathrm{Zn}$ $(22 \%)>\mathrm{Ti}(16 \%)>\mathrm{Al}(15 \%)>\mathrm{Mn}(13 \%)$. By contrast zinc and for some of the samples nickel are less adsorbed onto the organic matter and are present in significant proportions in the more mobile exchangeable and reducible fractions of the sludge. The greater concentration of zinc in the mobile fraction could possibly be due to the low $\mathrm{pH}$ of the sludge which limits precipitation of zinc carbonate as well as adsorption onto metal oxides. Conditioning of the sewage sludge with lime may improve the heavy metal immobility within the sludge particularly of the more mobile fractions such as zinc and nickel.

The presence of significant component of the heavy metals in the residual fractions is a good measure of the metal immobility and their non-bioavailability. Assessment of bioavailability of metals based on statutory regulation expressed in terms of total metals may be conservative and restrictive from the point of the use of sludge for agricultural applications. The data presented indicated the percentage 
immobility ranging from $10 \%$ to $70 \%$ with respect to the residual fractions of the metals which should be considered in the assessment of the suitability of the sludge for agricultural uses. Furthermore as pointed out earlier plant absorption of heavy metals is not always strongly correlated with total metals. Past studies discovered better association of plant heavy metal absorption with specific fractions. Cadmium and copper in plant grains were correlated with organic fraction of the metals while zinc being absorbed by plant was correlated with the reducible (oxide) fraction.

The data presented generally show relatively low concentrations of the reducible fractions for most of the metals which may be partly explained by the low $\mathrm{pH}$ of the sludge. A further stabilization with lime addition may be necessary to increase the $\mathrm{pH}$ of the sludge and to reduce the mobility of the metals that may be released with organic matter decomposition with time through adsorption onto metal oxides and precipitation at higher $\mathrm{pH}$.

While the presence of significant fraction of the metals in the organically bound oxidizable form is a certain measure of immobility according to the plateau theory which increases with time with increasing application of sludge containing organic matter. The time bomb theory considers by contrast the immobility as being only temporary with the possibility of release of heavy metals as the organic matter is decomposed with time. Therefore, while the speciation analysis is useful insight in assessing the relative immobility of the metals it has to be supported by ongoing monitoring of the accumulation of metals in sludge and the corresponding bioavailability of the metals with time.

Further plant trials with the prevailing soil conditions in Swaziland are necessary to obtain further information on bioavailability of the metals and their leaching potentials. It is known that addition of sludge to soil results in the redistribution of the heavy metals among the different fractions and the resulting fractions can be different from what has been revealed through sludge analysis. In addition the mobility and bioavailability of metals is further modified by soil texture and soil physico-chemical characteristics such as soil texture, $\mathrm{pH}$, soil organic matter, presence of metal oxides, etc. The redistribution of heavy metal fractions may occur because of change in $\mathrm{pH}$, organic matter content and other characteristics of the sewage-soil mixture [26]. The necessity for plant trials is further strengthened by the lack of consensus with respect to speciation analysis carried out by different researchers both on sludge and the soil partly due to the heterogeneity of the soil/sludge characteristics and partly because the method of determination of the speciation fractions are variable and no universal procedure has been adopted leading to results that may be difficult to compare with one another. he text edit has been completed, the paper is ready for the template. Duplicate the template file by using the Save As command, and use the naming convention prescribed by your conference for the name of your paper. In this newly created file, highlight all of the contents and import your prepared text file. You are now ready to style your paper; use the scroll down window on the left of the MS Word Formatting toolbar.

\section{Acknowledgements}

The authors would like to acknowledge and extend their thanks for the laboratory analysis service obtained from the Swaziland Water Services Corporation (SWSC) for the ICP-OES analysis of heavy metals in sludge samples.

\section{References}

[1] Alloway, B. J., and Jackson, A. P. (1991) The behavior of heavy metals in sewage sludge-amended soils. The Science of the Total Environment 100: 151-176.

[2] Alvarez, E.A., Mochon, M.C., Sanchez, J.C and Rodriguez, M.T. (2002) Heavy metal extractable forms in sludge from wastewater treatment plants. Chemosphere 47: 765-775.

[3] Bourg, A.C.M. (1988) Metal in aquatic and terrestrial systems: Sorption, speciation, and mobilization. pp. 3-32. In: Salomons, W. and Forstner, U. (Eds.). Chemistry and biology of solid waste. Berlin, Springer-Verlag.

[4] Brumer, G.W., Gerth, J. and Herms, U. (1986) Heavy metal species, mobility and availability in soils. Z. Pflanzenernaehr. Bodenk 149: 382.

[5] Brummer, G.W. (1986) Heavy metals species, mobility and availability in soils. pp. 169-192. In: Bernard,M., Brinckman, F.E. and Sadler, P.J. (Eds.). The Importance of chemical speciation in environment processes. Dahlem Konferenzen, Berlin, Heidelberg, Springer-Verlag,

[6] Calvet, R., Bourgeois, S. and Msaky, J.J. (1989) Some experiments on extraction of heavy metals present in soils. J. Environ. Anal. Chem 39: 31-45.

[7] Cambell, R.T. and Lester, J.N. (1988) The use of model compounds to elucidate metal forms in sewage sludge. Environ. Pollut. 50: 225.

[8] Camobreco, V.J., Richards, B.K., Steenhuis, T.S., Peverly, J.H., and McBride, M.B. (1996) Movement of heavy metals through undisturbed and homogenized soil columns. Soil Science 161:740-750.

[9] Carlson, C.E.A. and Morrison, G.M. (1992) Fractionation and toxicity of metals in sewage sludge. Environmental Technology 13: 1 .

[10] Chen, Y. (1996) Organic matter reactions involving micronutrients in soils and their effect on plants. Pp. 507-529. In: Piccolo A. (Ed.). Humic Substances in Terrestrial Ecosystems. Elsevier Science.

[11] Chlopecka, A. (1993) Forms of trace metals from inorganic sources in soils and amounts found in spring barley. Water Air Soil Pollut. 69: 127-134.

[12] Czekala, J. (1997) Chrom w glebie i roslinie. Wystepowanie, sorpcja i pobieranie w zaleznosci od jego formy i dawki, wlasciwosci srodowiska i nawozenia: (in Polish, with English abstract). Roczniki Akademii Rolniczej w Poznaniu 274: 90. 
[13] Egiarte, G., Corti, G., Pinto, M., Arostegui, J., Macías, F., Ruíz-Romero, E., Camps, M., and Arbestain, M. (2009) Fractionation of $\mathrm{Cu}, \mathrm{Pb}, \mathrm{Cr}$, and $\mathrm{Zn}$ in a Soil Column Amended with an Anaerobic Municipal Sewage Sludge, Water Air Soil Pollut, 198:133-148.

[14] Eick, M. J., Peak, J. D., Brady, P. V., and Pesek, J. D. (1999) Kinetics of lead adsorption/desorption on goethite: Residence time effect. Soil Science. 164: 28-39. doi:10.1097/ 00010694-199901000-00005.

[15] Elder, J.F. (1989) Metal biogeochemistry in surface-water systems - A review of principles and concepts. U.S. Geological Survey Circular 1013.

[16] Fendorf, S. (1995) Surface reactions of chromium in soils and waters. Geoderma: 67, 55-71. doi:10.1016/0016-7061(94)00062-F.

[17] Forbes, E. A., Posner, A. M. and Quirk, J. P. (1976) The specific adsorption of divalent $\mathrm{Cd}, \mathrm{Co}, \mathrm{Cu}, \mathrm{Pb}$, and $\mathrm{Zn}$ on goethite. Journal of Soil Science, 27: 154-166. doi:10.1111/j.1365- 2389.1976.tb01986.x.

[18] Gawdzik, J. and Gawdizik, B. (2012) Mobility of heavy metals in municipal sewage sludge from different throughput sewage treatment plants. Pol. J. Environ. Stud. 21(6): 1603-1611.

[19] Hanay, O., Hasar, H., Kocer, N.N. and Aslan, S. (2008) Evaluation for agricultural usage with speciation of heavy metals in a municipal sewage sludge. Bull. Environ Contam Toxicol 81:42-46.

[20] Jakubus, M and Czekała, J. (2001) Heavy Metal Speciation in Sewage Sludge. Polish Journal of Environmental Studies 10(4): 245-250.

[21] Jenne, E.A. (1968) Controls on $\mathrm{Mn}, \mathrm{Fe}, \mathrm{Co}, \mathrm{Ni}, \mathrm{Cu}$, and $\mathrm{Zn}$ concentration in soils and water: The significant role of hydrous Mn, and Fe oxides. pp. 337-387. In: R.F. Gould,R.F. (Ed.). Trace inorganics in water. Adv. In Chem. Ser. 73.. Am. Chem. Soc., Washington, DC.

[22] Kabata-Pendias, A. and Pendias H. (Eds.). (2002) Trace Elements in Soils and Plant. 3rd ed. Boca Raton, Florida, USA, CRC Press.

[23] Karapanagiotis, N. K., Sterritt, R. M., and Lester, J. N. (1991) Heavy metals complexation in sludge amended soil. The role of organic matter in metals retention. Environ. Technol. 12, $1107-1116$

[24] Keefer, R.F., Codling, E.E. and Singh, R.N. (1984) Fractionation of metal organic components extracted from a sludge-amended soil. Soil Sci. Soc. Am. J. 48:1054-1059.

[25] Kiekins, L. (1983) Behavior of heavy metals in soils. In: BERGLUND, S.; DAVIS, R.D.; L'HERMITE, P. (Eds.) Utilization of sewage sludge on land: rates of application and long-term effects of metals. Dordrecht: D. Reidel Publishing.

[26] Kikkila, O., Pennanen, T., Perkiomaki, J., Derome, J. and Fritze, H. (2002) Organic material as a copper immobilizing agent: a microcosm study on remediation. Basic and Applied Ecology 3: 245-253.

[27] Koepper, D.E. (1981) Lead: Understanding the minimal toxicity of lead in plants. pp. 55-76. In: Lepp, N.W. (Ed.). Effect of Heavy Metal Pollution on Plants, Vol. 1: Effect of trace metals on plant function. London: Applied Science
Publishers.

[28] Kuo, S., Jellum, E.J. and Baker, A.S. (1985) Effects of soil type, liming, and sludge application on zinc and cadmium availability to swiss chard. Soil Sci. 122:350-359.

[29] Lagerwerff, J. V., Biersdorf, G. T., and Brower, D. L. (1976) Retention of metals in sewage sludge: I. Constituent heavy metals. Journal of Environmental Quality 5: 19-23.

[30] Lindsay, W.L. (1972) Inorganic phase equilibria of micronutrients in soils. 41-57. In: Mortvdt, J.J., Gioradano, P.M. and Lindsay, W.L. (Eds.). Micronutrients in agriculture. Madison, Wisconsin: Soil Sci. Soc. Am.Proc.

[31] Loganathan, P., Duran, R.G. and Fuerstenan, D.W. (1977) Influence of $\mathrm{pH}$ on sorption of $\mathrm{Co} 2+, \mathrm{Zn} 2+$ and $\mathrm{Ca} 2+$ by a hydrous manganese oxide. Soil Sci. Soc Am. J. 41: 57- 62.

[32] Luoma, S.N. (1989) Can we determine the biological availability of sediment-bound trace elements? Hydrobiologia 176/177: 379-396.

[33] Marschener, B.H.U. and Wessolek, G. (1995) Effects of ameliorative additive on the adsorption and binding forms of heavy metals in a contaminated topsoil from a former sewage farm. Z. Pflanzenernahr. Boden. 158: 9.

[34] McBride, M. B. (1995) Toxic metal accumulation from agricultural use of sludge. Are USEPA regulations protective? Journal of Environmental Quality 24: 5-18.

[35] McBride, M.B., Tyler, L.D and Hovde, D.A. (1981) Cadmium adsorption by soils and uptake by plants as affected by soil chemical properties. Soil Sci. Soc. Am. J. 45:739-744.

[36] McLaren, R.G., and Crawford, D.V. (1973) Studies on soil copper: The specific adsorption of copper by soils. J. Soil Sci. 24:443-452.

[37] McLean, J. E., Bledsoe, B. E. (1992) Behavior of metals in soils. EPA Ground Water issue. EPA/540/S-92/018.

[38] Milacic, R. and Stupar, J. (1995) Fractionation and oxidation of chromium in tannery waste- and sewage sludge-amended soil. Environmental Science \& Technology 29: 506-514. doi:10.1021/es00002a029.

[39] Molenaar, S.W. and Beltrami, P. (1998) Heavy metal balances of an Italian soil as affect by sewage sludge and Bordeaux mixture applications. Journal of Environmental Quality 27: 828-835.

[40] Quevauviller, Ph., Rauret, G. and Griepink, B. (1993) Single and sequential extraction in sediments and soils. International Journal of Environ. Anal. Chem. 51: 231-235.

[41] Radosz, M. and Gawdzik, J. (2005) Impact assessment of microwave hygenization of sewage sludge on heavy metal mobility. Gaz, Woda I Technika Sanitarna 4: 24.

[42] Reneau, R.B., Berry, D.F. and Martens, D.C. (1990) Fate and transport of selected pollutants in soil. pp.14-44. In: Interntl. Symp. Environ. Pollut. Aric.,. Institute of Agricultural Science and Development, College of Agriculture, Seoul National University.

[43] Rivera, D.A., Pérezab, O.P. and Romána, F.R. (2013) LC-ICPMS speciation of arsenite and arsenate oxyanion mixtures during their adsorption with dried sludge. Anal. Methods, 2013,(5), 1583-1589. 
[44] Robert W.T., Xiu, He, Ahmed, A.M. Shuford, J.W. and Tadesse, W. (1995) Fractionation of residual cadmium, copper, nickel, lead and zinc in previously sludge-amended soil. J. Soil Sci. Plant Analysis. 26 (13\&14):2193-2204.

[45] Rosazlin, A., Che Fauziah, I., Rosenani, A.B., and Zauyah, S. (2007) Domestic sewage sludge application to an acid tropical soil: Part III. Fractionation Study of Heavy Metals in Sewage Sludge and Soils Applied with Sewage Sludge. Malaysian Journal of Soil Science 11: 81-95.

[46] Rudd, T.L. Mehrotra, A.I. Sterritt, R.M., Kirk, P.W.W., Cambell, J.A. and Lester, J.N. (1988) Characterization of metal forms in sewage sludge by chemical extraction and progressive acidification. The Science of the total Environment. 74: 149.

[47] Salas, F.M., Chino, M., Goto, S., Igarashi, T., Masujima, H. and Kumazawa, K. (1998) Forms and distribution of heavy metals in soils long term applied with sewage sludge. J. ISSAAS. 4: 64-98.

[48] Salomons, W. (1995) Environmental impact of metals derived from mining activities: Processes, predictions, prevention: Journal of Geochemical Exploration 52: 5-23.

[49] Sastre, I., Vicente, M.A. and Lobo, M.C. (2001) Behavior of cadmium and nickel in a soil amended with sewage sludge. Land Degradation and Development, 12: 27-33.

[50] Schaecke, W., Tannerberg, H. and Schilling, G. (2002) Behavior of heavy metals from sewage sludge in a Chernozem of the dry belt in Saxony- Anhalt/Germany. Journal of Plant Nutrition and Soil Science 165: 609-617.

[51] Schmidt, J.P. (1997) Understanding phytotoxicity thresholds for trace elements in land-applied sewage-sludge. Journal of Environmental Quality 26: 4-10.

[52] Silveira, M.L.A., Alleoni, L.R.F. and Guilherme, L.R.G. (2003) Bio solids and heavy metals in soils. Scientia Agricola 60: 793-806.

[53] Silviera, D.J. and Sommers, L.E. (1977) Extractability of copper, zinc, cadmium and lead in soils incubated with sewage sludge. J. Environ. Qual. 6: 47-52.

[54] Smedley, P.L. and Kinniburgh, K.G. (2002) Source and behaviour of arsenic in natural waters. British Geological Survey, Wallingford, Oxon OX10 8BB, U.K.

[55] Snoeyink, V.L. and Jenkins, D. (1980) Water chemistry. John Wiley and Sons, New York.
[56] Sommers, L.E. (1977) Chemical composition of sewage sludge and analysis of their potential use as fertilizers. J. Environ. Quality. 6: 225.

[57] Sparks, D.L. (1995) Environmental soil chemistry. 267p. San Diego: Academic Press.

[58] Sposito, G., Lund, L.J. and Chang, A.C. (1982) Trace metal chemistry in arid-zone fields amended with sewage sludge: I. Fractionation of $\mathrm{Ni}, \mathrm{Cu}, \mathrm{Zn}, \mathrm{Cd}$ and $\mathrm{Pb}$ in solid phases. Soil Sci. Am. J. 46: 260-264.

[59] Srikanth, R. and Reddy, S.R.P. (1991) Lead, cadmium and chromium levels in vegetables grown in urban sewage sludge in India. Food Chem. 40: 229-234.

[60] Stylianou, M.A., Demetra, K., Haralambous, K.J., Vassilis, J., Inglezakis, K.G. and Moustakas, M. D. L. (2007) Effect of acid treatment on the removal of heavy metals from sewage sludge. Desalination 215, 73-81.

[61] Tessier, A., Campbell, P. G. C., and Bisson, M. (1979) Sequential extraction procedure for the speciation of particulate trace metals. Analytical Chemistry, 51: 844-850.

[62] Tuin, B.J.W. and Tels, M. (1990) Distribution of six heavy metals in contaminated clay soils before and after extractive cleaning. Environ. Tech. 11: 935-948.

[63] USEPA. (2012) METHOD 3050B. Acid diegsestion of sediments, sludge and soils. http://www.epa.gov/osw/hazard/testmethods/sw846/online/3 _series.htm.

[64] Wan Noridah, W.A. (2000) Fractionation of heavy metals in sewage sludge treated soils. Final year project. Department of Soil Management, Faculty of Agriculture, University Putra Malaysia, Malaysia.

[65] Wang, C., Hu, X., Chen, M.L. and Wu, Y.H . (2005) Total concentrations and fractions of $\mathrm{Cd}, \mathrm{Cr}, \mathrm{Pb}, \mathrm{Cu}, \mathrm{Ni}$ and $\mathrm{Zn}$ in sewage sludge from municipal and industrial wastewater treatment plants. J Hazard Mater 119:245-249. doi:10.1016/j.jhazmat.2004.11.023.

[66] Wang, C., Li, C.X., Ma, H.T., Qian, J. and, Zhai, J.B. (2006) Distribution of extractable fractions of heavy metals in sludge during the wastewater treatment process. J Hazard Mater 137:1277-1283. doi:10.1016/j.jhazmat.2006.04.026.

[67] Zhang, D., Shan, X. and Li, F. (1998) Comparison of sequential extraction procedures for speciation analysis of metals in soils and plant availability. Soil Sci. Plant Anal. 29(7\&8): 1023-1034. 